Jurnal UJMC, Volume 5, Nomor 2, Hal. 11 - 18

pISSN : 2460-3333 eISSN : 2579-907X

\title{
Perbandingan Kinerja Angkutan Umum Konvensional dan Angkutan Umum Berbasis Online di Banyuwangi
}

\author{
Dimas Fitroh Ariadi ${ }^{1}$, Wahyu Naris Wari ${ }^{2}$, Siska Aprilia Hardiyanti ${ }^{3}$ \\ ${ }^{1}$ Politeknik Negeri Banyuwangi, dimasfitrohariadi291298@gmail.com \\ ${ }^{2}$ Politeknik Negeri Banyuwangi, naris@poliwangi.ac.id \\ ${ }^{3}$ Politeknik Negeri Banyuwangi, siska_aprilia3@poliwangi.ac,id
}

\begin{abstract}
Public transportation in Banyuwangi was not only conventional, but also online based public transportation. There were advantages and disadvantages to each of the public transportation. Each community has a different assessment of the performance of public transportation. The purpose of this study was to determine the comparative performance of two public transportation. This research uses the importance performance analysis (IPA) method. IPA method was used to analyze date regarding service performance and interests. Based on the results of a survey conducted for conventional public transportation that needs to be improved were items in quadrant A or high respondent's expectation level, but the performance of service low, namely regarding room temperature facilities that function well and the driver can guarantee the safety of service users. For online based public transportation that needs to be improved was the timeliness items taken, the coating on the vehicles's glass in order to reduce direct sunlight and the driver could guarantee the safety of service users.
\end{abstract}

Keywords: Performance Comparison, Conventional Transport, Online Transport, IPA, SPSS

\begin{abstract}
Abstrak. Angkutan umum di Banyuwangi saat ini, bukan hanya angkutan umum konvensional, namun juga terdapat angkutan berbasis online. Terdapat kelebihan dan kekurangan pada masing-masing angkutan umum tersebut. Setiap masyarakat mempunyai penilaian yang berbeda terhadap kinerja angkutan umum tersebut. Tujuan dari penelitian ini adalah untuk mengetahui perbandingan kinerja dari kedua angkutan umum tersebut. Penelitian ini menggunakan metode importance performance analysis (IPA). Metode IPA adalah suatu metode yang digunakan untuk menganalisa data mengenai kinerja pelayanan dan kepentingan. Berdasarkan hasil survei yang dilakukan untuk angkutan umum konvensional yang perlu di tingkatkan kinerjanya adalah item yang masuk kuadran A atau tingkat harapan responden tinggi tetapi kinerja pelayanannya rendah yaitu tentang fasilitas temperatur suhu ruangan yang berfungsi baik dan pengemudi dapat menjamin keselamatan pengguna jasa. Bagi angkutan umum berbasis online yang perlu di tingkatkan kinerjanya adalah item tentang ketepatan waktu yang ditempuh, lapisan pada kaca kendaraan guna mengurangi cahaya matahari secara langsung dan pengemudi dapat menjamin keselamatan pengguna jasa.
\end{abstract}

Kata kunci: Perbandingan Kinerja, Angkutan Konvensional, Angkutan Online, IPA, SPSS 


\section{Pendahuluan}

Angkutan umum di Banyuwangi saat ini bukan hanya angkutan umum konvensional, namun juga terdapat angkutan berbasis online. Angkutan umum konvensional merupakan alternatif yang digunakan pemerintah untuk memenuhi kebutuhan manusia dalam aktifitas sehari-hari. Angkutan umum konvensional merupakan angkutan umum yang sangat mudah ditemui seperti di pasar, terminal, stasiun dan tempat instansi lainnya. Jumlah angkutan umum konvensional cukup banyak di Indonesia salah satunya di Kabupaten Banyuwangi. Angkutan umum konvensional memiliki ikatan atau jaminan hukum karena angkutan umum konvensional tersebut berada dibawah pengawasan pemerintah.

Angkutan umum berbasis online adalah angkutan umum yang dibentuk oleh seseorang atau kelompok dengan menggunakan suatu aplikasi tertentu, dimana konsumen diharapkan dapat memesan suatu sarana angkutan umumberbais online melalui smartphone yang berupa aplikasi dimana konsumen dapat melakukan pemesanan menggunakan aplikasi tersebut secara detail. Transportasi berbasis online mulai berkembang di Kota Banyuwangi pada awal tahun 2017. Seiring dengan munculnya angkutan umum berbaisis online di Banyuwangi yang semakin pesat maka dari itu dilakukan penelitian untuk membandingkan kinerja kedua angkutan umum tersebut agar pemilik jasa angkutan umum tersebut dapat mengetahui kekurangan atau permasalahan dalam kinerja pelayanannya menurut responden.

\section{Tinjauan Pustaka}

\subsection{Angkutan Umum}

Menurut keputusan Direktur Jenderal perhubungan darat [1], kendaraan umum adalah setiap kendaraan bermotor yang disediakan untuk digunakan oleh umum dengan dipungut bayaran.

\subsection{Pengertian Tingkat Kepuasan}

Kepuasan pelanggan merupakan salah satu kunci keberhasilan usaha. Hal ini dikarenakan dengan memuaskan pelanggan, perusahaan dapat meningkatkan tingkat keuntungannya. Konsumen dalam menggunakan jasa tertentu akan menghasilkan tingkat kepuasan tertentu. Dari tampilan pelayanan, maka pelayanan yang diberikan tidak mungkin selalu sama dengan harapan konsumen atau penumpang. Dalam mengukur kepuasan penumpang ada lima dimensi besar melalui kualitas jasa yaitu Reability (keandalan), Responsiveness (daya tanggap), Assurance (jaminan), Emphaty (empati) dan Tangible (kasat mata).

\subsection{Teknik Sampling}

Teknik sampling adalah suatu cara untuk menentukan jumlah sampel atau jumlah responden. Untuk perhitungan jumlah sampel minimum apabila jumlah populasi (n) tidak diketahui, maka besar sampel dihitung dengan rumus Lemeshow berikut ini : 


$$
n=\frac{Z^{2} P(1-p)}{d^{2}}
$$

Dengan :

$n=$ Number of Samples (jumlah sampel)

$Z=$ Skor $z$ pada kepercayaan

$\mathrm{p}=$ Estimasi Maksimal

$\mathrm{d}=$ Presisi

\subsection{Bobot Penilaian}

Dalam hal ini kepentingan pelayanan diranking menggunakan skala lima tingkat (skala likert) seperti pada tabel 1 dan untuk tingkat kinerja/aspek kepuasan penumpang diranking dengan menggunakan skala lima tingkat (skala likert) seperti pada tabel 2.

Tabel 1. Bobot Kuantitatif Tingkat Harapan

\begin{tabular}{ccc}
\hline No & Jawaban & Bobot \\
\hline 1 & Sangat Tidak Penting & 1 \\
2 & Tidak Penting & 2 \\
3 & Cukup Penting & 3 \\
4 & Penting & 4 \\
5 & Sangat Penting & 5 \\
\hline Sumber: $[2]$ & &
\end{tabular}

Tabel 2. Bobot Kuantitatif Tingkat Kinerja Pelayanan

\begin{tabular}{ccc}
\hline No & Jawaban & Bobot \\
\hline 1 & Sangat Tidak Baik & 1 \\
2 & Tidak Baik & 2 \\
3 & Cukup Baik & 3 \\
4 & Baik & 4 \\
5 & Sangat Baik & 5 \\
\hline
\end{tabular}

\section{Metodologi Penelitian}

\subsection{Data}

Data yang dibutuhkan adalah data yang didapat dari pengambilan langsung pada lokasi penelitian. Data primer yang dibutuhkan adalah data kepuasan penumpang di dapat dari pengolahan data kuesioner dengan menggunakan metode Importance Performance Analysis (IPA), yang mana pada analisis ini membandingkan antara tingkat harapan responden terhadap tingkat kinerja pelayanan dengan mengolah data menggunakan diagram kartesius, yang nantinya akan diketahui pada kuadran mana tercapainya tingkat kepuasan penumpang.

\subsection{Sampel}

Dalam mencari jumlah sempel menggunakan rumus Lemeshow (Pers.1) diatas dengan nilai $Z=1,96 ; p=0,5$; dan $d=0,10$, maka jumlah sempel minimal adalah 96,04 kemudian dibulatkan menjadi 100 reponden. 


\section{Hasil dan Pembahasan}

Tabel 3. Variabel dan Simbol Tingkat Kinerja dan Kepentingan

\begin{tabular}{|c|c|c|c|c|}
\hline No & Variabel & Item Pertanyaan & $\begin{array}{l}\text { Simbol } \\
\text { Variabel } \\
\text { Tingkat } \\
\text { Kinerja } \\
\end{array}$ & $\begin{array}{c}\text { Simbol } \\
\text { Variabel } \\
\text { Tingkat } \\
\text { Kepentingan } \\
\end{array}$ \\
\hline \multirow[t]{3}{*}{1.} & $\begin{array}{l}\text { Penampilan Fisik } \\
\text { (Tangible) }\end{array}$ & $\begin{array}{l}\text { Fasilitas temperatur suhu } \\
\text { ruangan yang berfungsi baik }\end{array}$ & $\mathrm{X}_{1.1}$ & $\mathrm{Y}_{1.1}$ \\
\hline & & $\begin{array}{l}\text { Lapisan pada kaca kendaraan } \\
\text { guna mengurangi cahaya } \\
\text { matahari secara langsung }\end{array}$ & $\mathrm{X}_{1.2}$ & $\mathrm{Y}_{1.2}$ \\
\hline & & Kondisi kebersihan kendaraan & $\mathrm{X}_{1.3}$ & $\mathrm{Y}_{1.3}$ \\
\hline \multirow[t]{3}{*}{2.} & $\begin{array}{l}\text { Kehandalan } \\
\text { (Realiability) }\end{array}$ & $\begin{array}{l}\text { Informasi tentang rute yang } \\
\text { dilayani, tata cara mengangkut } \\
\text { orang da cara berlalulintas }\end{array}$ & $\mathrm{X}_{2.1}$ & $\mathrm{Y}_{2.1}$ \\
\hline & & $\begin{array}{l}\text { Melayani rute sesuai ijin } \\
\text { trayek yang diberikan }\end{array}$ & $\mathrm{X}_{2.2}$ & $\mathrm{Y}_{2.2}$ \\
\hline & & $\begin{array}{l}\text { Ketepatan waktu yang } \\
\text { ditempuh dalam berkendara }\end{array}$ & $\mathrm{X}_{2.3}$ & $\mathrm{Y}_{2.3}$ \\
\hline \multirow[t]{3}{*}{3.} & $\begin{array}{l}\text { Tanggapan } \\
\text { (Responsiveness) }\end{array}$ & $\begin{array}{l}\text { Pengemudi menyediakan } \\
\text { perlengkapan pertolongan } \\
\text { pertama }(\mathrm{P} 3 \mathrm{~K})\end{array}$ & $\mathrm{X}_{3.1}$ & $\mathrm{Y}_{3.1}$ \\
\hline & & $\begin{array}{l}\text { Menyiapkan fasilitas } \\
\text { keselamatan berupa alat } \\
\text { pemadam api ringan }\end{array}$ & $\mathrm{X}_{3.2}$ & $\mathrm{Y}_{3.2}$ \\
\hline & & $\begin{array}{l}\text { Pemasangan setiker berupa } \\
\text { nomer telefon untuk } \\
\text { pengaduan pengguna jasa }\end{array}$ & $\mathrm{X}_{3.3}$ & $\mathrm{Y}_{3.3}$ \\
\hline \multirow[t]{3}{*}{4.} & Empati (Emphaty) & $\begin{array}{l}\text { Menutup pintu saat kendaraan } \\
\text { berjalan }\end{array}$ & $\mathrm{X}_{4.1}$ & $\mathrm{Y}_{4.1}$ \\
\hline & & $\begin{array}{l}\text { Tempat duduk prioritas bagi } \\
\text { penyandang cacat, manusia } \\
\text { usia lanjut, anak-anak dan ibu } \\
\text { hamil }\end{array}$ & $\mathrm{X}_{4.2}$ & $\mathrm{Y}_{4.2}$ \\
\hline & & $\begin{array}{l}\text { Sikap dan perilaku yang baik, } \\
\text { hormat dan ramah terhadap } \\
\text { pengguna jasa }\end{array}$ & $\mathrm{X}_{4.3}$ & $\mathrm{Y}_{4.3}$ \\
\hline \multirow[t]{3}{*}{5.} & Jaminan (Assurance) & $\begin{array}{l}\text { Pengemudi dapat menjamin } \\
\text { keselamatan pengguna jasa }\end{array}$ & $\mathrm{X}_{5.1}$ & $\mathrm{Y}_{5.1}$ \\
\hline & & $\begin{array}{l}\text { Menaikan dan menurunkan } \\
\text { pengguna jasa ditempat yang } \\
\text { ditentukan }\end{array}$ & $\mathrm{X}_{5.2}$ & $\mathrm{Y}_{5.2}$ \\
\hline & & $\begin{array}{l}\text { Mengangkut penumpang } \\
\text { sesuai daya angkut yang } \\
\text { diijinkan }\end{array}$ & $\mathrm{X}_{5.3}$ & $\mathrm{Y}_{5.3}$ \\
\hline
\end{tabular}

Sumber: [3] 
Tabel 4. Perhitungan Nilai Rata-Rata Tingkat Kinerja Dan Tingka Kepentingan Pada Angkutan Umum Konvensional dan Angkutan Umum berbasis Online di Banyuwangi (konvensional)

\begin{tabular}{|c|c|c|c|c|c|}
\hline NO & PERTANYAAN & $\begin{array}{c}\text { Penilaian } \\
\text { Tingkat } \\
\text { Kepentingan }\end{array}$ & $\bar{Y}$ & $\begin{array}{c}\text { Penilaian } \\
\text { Tingkat } \\
\text { Kinerja }\end{array}$ & $\bar{x}$ \\
\hline \multicolumn{6}{|c|}{ A. Penampilan Fisik (Tangible) } \\
\hline 1. & $\begin{array}{l}\text { Fasilitas temperatur suhu ruangan yang } \\
\text { berfungsi baik }\end{array}$ & 456 & 4,56 & 390 & 3,90 \\
\hline 2. & $\begin{array}{l}\text { Lapisan pada kaca kendaraan guna } \\
\text { mengurangi cahaya matahari secara } \\
\text { langsung }\end{array}$ & 432 & 4,32 & 389 & 3,89 \\
\hline & Kondisi kebersihan kendaraan & 444 & 4,44 & 409 & 4,09 \\
\hline \multicolumn{6}{|c|}{ B. Kehandalan (Realiability) } \\
\hline & $\begin{array}{l}\text { Informasi tentang rute yang dilayani, } \\
\text { tata cara mengangkut orang da cara } \\
\text { berlalulintas }\end{array}$ & 449 & 4,49 & 406 & 4,06 \\
\hline & $\begin{array}{l}\text { Melayani rute sesuai ijin trayek yang } \\
\text { diberikan }\end{array}$ & 439 & 4,39 & 402 & 4,02 \\
\hline & $\begin{array}{l}\text { Ketepatan waktu yang ditempuh dalam } \\
\text { berkendara }\end{array}$ & 423 & 4,23 & 395 & 3,95 \\
\hline \multicolumn{6}{|c|}{ C. Tanggapan (Responsiveness) } \\
\hline & $\begin{array}{l}\text { Pengemudi menyediakan perlengkapan } \\
\text { pertolongan pertama (P3K) }\end{array}$ & 438 & 4,38 & 397 & 3,97 \\
\hline & $\begin{array}{l}\text { Menyiapkan fasilitas keselamatan } \\
\text { berupa alat pemadam api ringan }\end{array}$ & 416 & 4,16 & 384 & 3,84 \\
\hline & $\begin{array}{l}\text { Pemasangan setiker berupa nomer } \\
\text { telefon untuk pengaduan pengguna jasa }\end{array}$ & 411 & 4,11 & 377 & 3,77 \\
\hline \multicolumn{6}{|c|}{ D. Empati (Emphaty) } \\
\hline NO & PERTANYAAN & $\begin{array}{c}\text { Penilaian } \\
\text { Tingkat } \\
\text { Kepentingan }\end{array}$ & $\bar{Y}$ & $\begin{array}{c}\text { Penilaian } \\
\text { Tingkat } \\
\text { Kinerja } \\
\end{array}$ & $\bar{x}$ \\
\hline 1. & $\begin{array}{l}\text { Menutup pintu saat kendaraan } \\
\text { berjalan }\end{array}$ & 475 & 4,75 & 423 & 4,23 \\
\hline 2. & $\begin{array}{l}\text { Tempat duduk prioritas bagi } \\
\text { penyandang cacat, manusia usia } \\
\text { lanjut, anak-anak dan ibu hamil }\end{array}$ & 432 & 4,32 & 381 & 3,81 \\
\hline & $\begin{array}{l}\text { Sikap dan perilaku yang baik, } \\
\text { hormat dan ramah terhadap } \\
\text { pengguna jasa }\end{array}$ & 416 & 4,16 & 396 & 3,96 \\
\hline \multicolumn{6}{|c|}{ E. Jaminan (Assurance) } \\
\hline & $\begin{array}{l}\text { Pengemudi dapat menjamin } \\
\text { keselamatan pengguna jasa }\end{array}$ & 487 & 4,87 & 395 & 3,95 \\
\hline 2. & $\begin{array}{l}\text { Menaikan dan menurunkan } \\
\text { pengguna jasa ditempat yang } \\
\text { ditentukan }\end{array}$ & 425 & 4,25 & 391 & 3,91 \\
\hline \multirow[t]{2}{*}{3.} & $\begin{array}{l}\text { Mengangkut penumpang sesuai } \\
\text { daya angkut yang diijinkan }\end{array}$ & 424 & 4,24 & 393 & 3,93 \\
\hline & Total $\bar{x}$ dan $\bar{Y}$ & 6567 & 65,67 & 5928 & 59,28 \\
\hline
\end{tabular}

Sumber: Pengolahan Data Kuesioner, 2019 
Tabel 5. Perhitungan Nilai Rata-Rata Tingkat Kinerja Dan Tingka Kepentingan Pada Angkutan Umum Konvensional dan Angkutan Umum berbasis Online di Banyuwangi (online)

\begin{tabular}{|c|c|c|c|c|c|}
\hline NO & PERTANYAAN & $\begin{array}{c}\text { Penilaian } \\
\text { Tingkat } \\
\text { Kepentingan }\end{array}$ & $\bar{Y}$ & $\begin{array}{c}\text { Penilaian } \\
\text { Tingkat } \\
\text { Kinerja }\end{array}$ & $\bar{x}$ \\
\hline \multicolumn{6}{|c|}{ A. Penampilan Fisik (Tangible) } \\
\hline 1. & $\begin{array}{l}\text { Fasilitas temperatur suhu ruangan } \\
\text { yang berfungsi baik }\end{array}$ & 460 & 4,60 & 442 & 4,42 \\
\hline 2. & $\begin{array}{l}\text { Lapisan pada kaca kendaraan guna } \\
\text { mengurangi cahaya matahari secara } \\
\text { langsung }\end{array}$ & 434 & 4,34 & 442 & 4,42 \\
\hline 3. & Kondisi kebersihan kendaraan & 423 & 4,23 & 448 & 4,48 \\
\hline \multicolumn{6}{|c|}{ B. Kehandalan (Realiability) } \\
\hline 1. & $\begin{array}{l}\text { Informasi tentang rute yang } \\
\text { dilayani, tata cara mengangkut } \\
\text { orang da cara berlalulintas }\end{array}$ & 443 & 4,43 & 459 & 4,59 \\
\hline 2. & $\begin{array}{l}\text { Melayani rute sesuai ijin trayek } \\
\text { yang diberikan }\end{array}$ & 432 & 4,32 & 451 & 4,51 \\
\hline & $\begin{array}{l}\text { Ketepatan waktu yang ditempuh } \\
\text { dalam berkendara }\end{array}$ & 426 & 4,26 & 450 & 4,50 \\
\hline \multicolumn{6}{|c|}{ C. Tanggapan (Responsiveness) } \\
\hline 1. & $\begin{array}{l}\text { Pengemudi menyediakan } \\
\text { perlengkapan pertolongan pertama } \\
\text { (P3K) }\end{array}$ & 419 & 4,19 & 412 & 4,12 \\
\hline 2. & $\begin{array}{l}\text { Menyiapkan fasilitas keselamatan } \\
\text { berupa alat pemadam api ringan }\end{array}$ & 409 & 4,09 & 413 & 4,13 \\
\hline 3. & $\begin{array}{l}\text { Pemasangan setiker berupa nomer } \\
\text { telefon untuk pengaduan pengguna } \\
\text { jasa }\end{array}$ & 458 & 4,58 & 432 & 4,32 \\
\hline \multicolumn{6}{|c|}{ D. Empati (Emphaty) } \\
\hline 1. & $\begin{array}{l}\text { Menutup pintu saat kendaraan } \\
\text { berjalan }\end{array}$ & 463 & 4,63 & 469 & 4,69 \\
\hline 2. & $\begin{array}{l}\text { Tempat duduk prioritas bagi } \\
\text { penyandang cacat, manusia usia } \\
\text { lanjut, anak-anak dan ibu hamil }\end{array}$ & 432 & 4,32 & 422 & 4,22 \\
\hline 3. & $\begin{array}{l}\text { Sikap dan perilaku yang baik, } \\
\text { hormat dan ramah terhadap } \\
\text { pengguna jasa }\end{array}$ & 427 & 4,27 & 439 & 4,39 \\
\hline \multicolumn{6}{|c|}{ E. Jaminan (Assurance) } \\
\hline & $\begin{array}{l}\text { Pengemudi dapat menjamin } \\
\text { keselamatan pengguna jasa }\end{array}$ & 465 & 4,65 & 442 & 4,42 \\
\hline 2. & $\begin{array}{l}\text { Menaikan dan menurunkan } \\
\text { pengguna jasa ditempat yang } \\
\text { ditentukan }\end{array}$ & 445 & 4,45 & 457 & 4,57 \\
\hline \multirow[t]{2}{*}{3.} & $\begin{array}{l}\text { Mengangkut penumpang sesuai } \\
\text { daya angkut yang diijinkan }\end{array}$ & 433 & 4,33 & 453 & 4,53 \\
\hline & Total $\bar{x}$ dan $\bar{Y}$ & 6569 & 65,69 & 6631 & 66,31 \\
\hline
\end{tabular}

Sumber: Pengolahan Data Kuesioner, 2019 


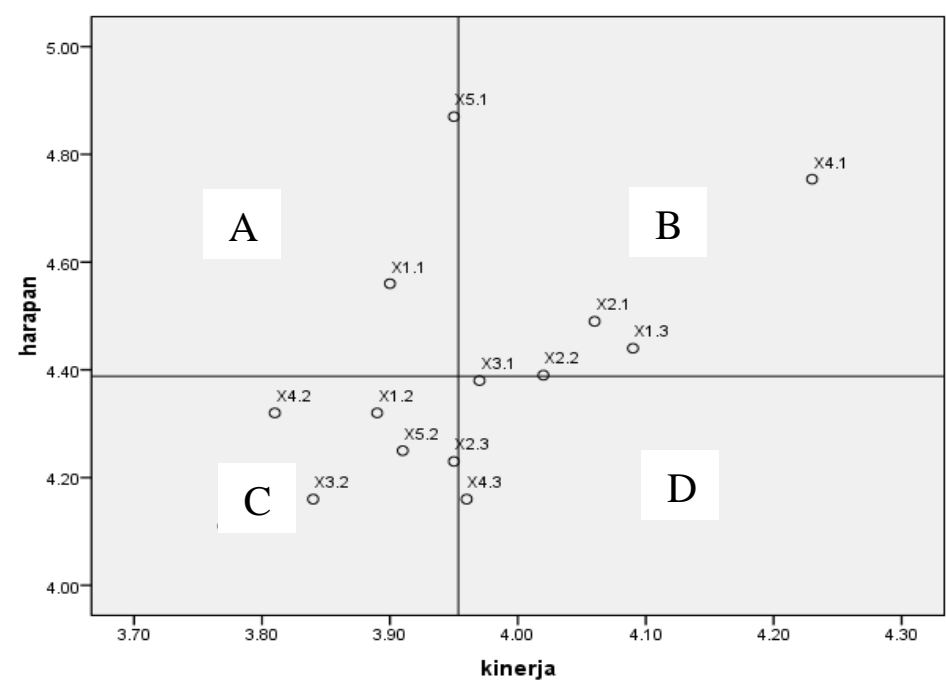

Gambar 1. Diagram Kartesius Pada Angkutan Umum konvensional (Pengolahan Data, 2019)

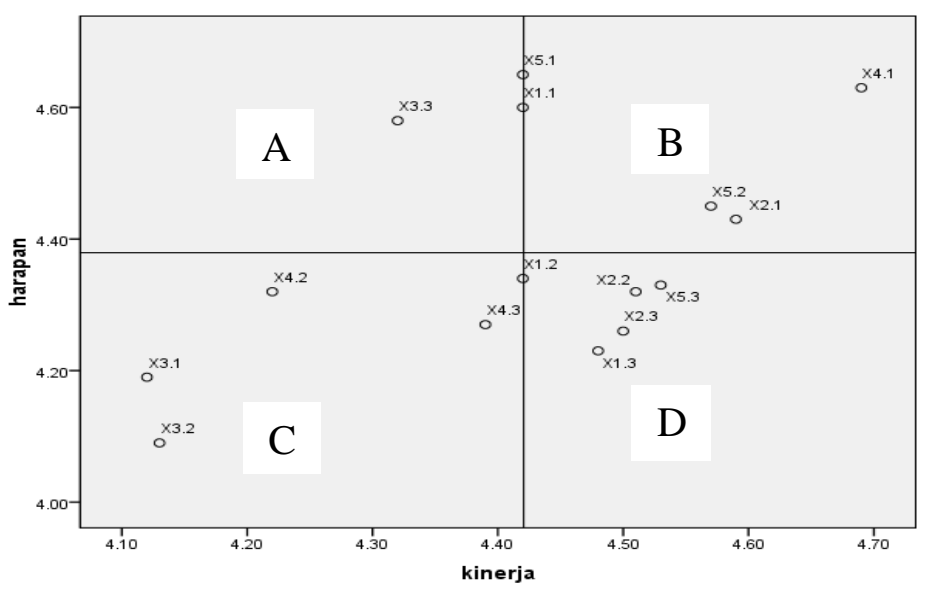

Gambar 2. Diagram Kartesius Pada Angkutan Umum Berbasis Online (Pengolahan Data, 2019)

Berdasarkan tabel diatas analisa dalam bentuk diagram kartesius bahwa item yang masuk dalam kuadran $\mathrm{A}$ atau prioritas utama untuk konvensional 2 item untuk online 3 item, yang masuk dalam kuadran B atau pertahankan prestasi untuk konvensional 5 item untuk online 3 item, yang masuk dalam kuadran $\mathrm{C}$ atau prioritas rendah untuk konvensional 7 item untuk online 5 item, yang masuk dalam kuadran D atau berlebihan untuk konvensional 2 item untuk online 4 item. Dalam digram kartesius kuadran yang terbaik adalah pada kuadran B atau harapan responden tinggi dan kinerja pelayanannya tinggi. Item yang masuk dalam kudran B utuk angkutan umum konvensional adalah item tentang Kondisi kebersihan kendaraan, Informasi tentang rute yang dilayani, tata cara mengangkut orang da cara berlalulintas, Melayani rute sesuai ijin trayek yang diberikan, Pengemudi menyediakan perlengkapan pertolongan pertama (P3K) dan Menutup pintu saat kendaraan berjalan. Sedangkan untuk angkutan umum berbasis online yaitu item tentang Informasi tentang rute yang dilayani, tata cara mengangkut orang da cara berlalulintas, Menutup pintu saat kendaraan berjalan, menaikan dan menurunkan 
pengguna jasa ditempat yang ditentukan. Untuk item yang masuk dalam kudran B atau prestasi harus dipertahankan.

\section{Kesimpulan}

Dari hasil analisis yang dilakukan untuk angkutan umum konvensional yang perlu ditingkatkan kinerjanya adalah item yang masuk kuadran A atau tingkat harapan responden tinggi tetapi kinerja pelayanannya rendah yaitu tentang fasilitas temperatur suhu ruangan yang berfungsi baik dan pengemudi dapat menjamin keselamatan pengguna jasa. Untuk angkutan umum berbasis online yang perlu ditingkatkan kinerjanya adalah item tentang ketepatan waktu yang ditempuh, lapisan pada kaca kendaraan guna mengurangi cahaya matahari secara langsung dan pengemudi dapat menjamin keselamatan pengguna jasa.

\section{Daftar Pustaka}

[1] D. J. P. Darat, "Keputusan Direktur Jenderal Perhubungan Darat Nomor: SK. 687/AJ," 2002.

[2] R. Likert, "A technique for the measurement of attitudes.," Arch. Psychol., 1932.

[3] Peraturan Menteri Perhubungan RI No. PM 98, Standar Pelayanan Minimal Angkutan Orang dengan Kendaraan Bermotor Umum dalam Trayek. 2013. 